\title{
Correspondence
}

\section{Use of CS gas}

Sir: I am writing on behalf of the Patients' and Carers' Liaison Group of the Royal College of Psychiatrists. We are receiving an increasing number of reports about the use of CS gas in the management of violent incidents where psychiatric patients are involved. In a number of instances, there is a mounting sense of disquiet about the necessity for use of this gas, the effect it has on patients, bystanders and staff who may be involved, and the lack of clarity about guidelines for its use.

It has come to our notice that the guidelines for use of CS gas have been drawn up by the Association of Chief Police Officers. These are held in local police stations and are only accessible to people who the police themselves deem as being appropriate. In view of the fact that these guidelines are not openly available, it may be that local psychiatrists would wish to request to see them as their patients are being involved.

The Patients' and Carers' Liaison Group would be pleased to receive reports about the use of CS gas on patients, particularly in cases where there is some concern about whether it was an appropriate course of action to take.

T. M. HARRISON, Consultant Psychiatrist, Member of Patients' and Carers' Liaison Group of the Royal College of Psychiatrists

\section{Medical staffing crisis}

Sir: Jenkins \& Scott (Psychiatric Bulletin, April 1998, 22, 239-241) outline the main concerns regarding the difficulty in recruitment of and retention of psychiatrists within the profession. One of their four suggested responses includes improving job plans and working conditions.

While this approach can offer the opportunity for subtle alterations in working practice, the majority of psychiatrists will notice no change in their experience of their working week. Few, if any, psychiatrists in purely clinical posts have the opportunity to take a sabbatical, resulting in those entering psychiatry (already perceived as a high stress speciality) appearing to be on a career path labelled "Go straight to your retirement at 55. Do not pass Go!".

The entire career structure for psychiatrists needs to be examined to allow not only flexible working within a job but the ability to move in and out of the speciality without accruing a career penalty.

In The Age of Unreason, Charles Handy describes the concept of a variegated career, with periods of work alternating with periods of study. Psychiatry needs to encourage an innovative, unorthodox and varied career structure from junior doctor level until retirement. Only then can it be expected that psychiatrists will return and enthusiastically respond to the ever increasing demands of a career in psychiatry.

HANDY, C. (1995) The Age of Unreason, p. 127. London: Arrow Books.

SUJATA UNNITHAN, Consultant Psychiatrist, Options Community Drug Team, Worthing Priority Care NHS Trust, 24 Grafton Road, Worthing BN11 1QP

\section{Improving treatment adherence}

Sir: I would like to add some further points to the excellent review of treatment adherence by Sair et al (Psychiatric Bulletin. February 1998, 22, 77-81). Rather than being especially critical of psychiatric patients in their failure to stick to treatment regimens, we should acknowledge that non-compliance is an ubiquitous phenomenon, well known to our colleagues in other fields of medicine. It may be more accurate and helpful to see any such lapses as largely normal behaviour. Think of the last time you tried to complete a course of antibiotics.

With any treatment the motivation to continue declines inversely with the time elapsed from the index illness. This problem is compounded if stopping medication has no immediate consequences, as is the case with many psychotropic drugs. Demonstrating an appreciation of the difficulties of long-term medication is a useful opening gambit in the business of developing the type of collaborative approach the article advocates (Goldstein, 1992).

Of course, for a significant proportion of our patients, non-adherence is driven by illness issues, be they delusional ideas, disorganisation or memory impairment. The use of the Mental Health Act 1993 has been shown to improve compliance, possibly by allowing the patient to experience the benefits of extended treatment (Sensky et al, 1991). It is to be regretted that the current community care order does not enable 
such treatment to be delivered in the patient's home.

Finally, we should remember that for each uncooperative patient there is likely to be an over-compliant one. Quietly tolerating adverse effects from over zealous drug regimens, they may believe that 'the doctor knows best' or indeed be unaware that they are free to refuse treatment (Eastwood \& Pugh, 1997).

EASTWOOD, N. \& PUGH, R. (1997) Long-term medication in depot clinics and patients' rights: an issue for assertive outreach. Psychiatric Bulletin, 21, 273-275.

GoldSTEIN, M. J. (1992) Psychosocial strategies for maximising the effects of psychotropic medications for schizophrenia and mood disorders. Psychopharmacology Bulletin, 28, 237-240.

Sensky, T., Hughes, T. \& HiRsch, S. (1991) Compulsory psychiatric treatment in the community. I. A controlled study of compulsory community treatment of patients under the Mental Health Act: special characteristics of patients treated and impact of treatment. British Joumal of Psychiatry. 158. 792-799.

ElizaBeTH H. HARE, Specialist Registrar, East and Mid Lothian Trust, Herdmanflat Hospital, Aberlady Road, Haddington EH41 3BU

\section{Care Programme Approach: equivalent developments in Australia}

Sir: The Care Programme Approach (CPA) has clearly generated a significant amount of controversy in Britain. The Victorian Government (Australia) has published a series of policy documents (Psychiatric Services Division, 1994) which have created expectations that a case management model of care, similar to the CPA system, will be provided by all public psychiatric services. The recommended model includes formal intake, the appointment of a case manager, team review, individual service planning and case closure for all patients treated. This model is being gradually adopted statewide as funding agreements demand.

The Geelong psychiatric services embarked on adopting this case management model in 1994. As discussed by Ferguson (1996), we found these attempts, without an integrated patient information system, laborious, frustrating to monitor and greeted with considerable resistance.

Over the past three years we have designed new patient record documents corresponding to each of the processes in the case management model and a computerised mental health patient information management system (MH-PIMS), on which is recorded some basic data on each patient and allows each patient to be tracked through the system until case closure. MH-PIMS produces reports on a weekly basis, which are of value to teams in conducting their everyday business and review meetings. This includes lists of patients due for review; patients discharged from the in-patient unit in the previous month and case-load lists.

In the year ending October 1997, the average active case-load of case managers was 25; each case manager took on an average of 23 new cases and discharged 22.5 cases in the same period. This throughput was maintained by adhering to the case management model and monitoring this in individual supervision and in team meetings.

Although the introduction of this structured system has been demanding on management and challenging to clinicians, our staff now have a positive attitude towards the system and we believe our perseverance has yielded results.

Ferguson, B. (1996) Principles of computers in care management and the care programme approach British Journal of Hospital Medicine, 56, 466-469.

PSYCHIATRIC SERVICES DIVISION (1994) Victoria's Mental Health Service, The Framework for Service Delivery. Victoria: Department of Health and Community Services, Victorian Government.

T. Callaly, Chief of Service, Geelong Hospital, Division of Psychiatry, Swanston Centre, Cnr Myers and Swanston Street, Geelong, Victoria, Australia

\section{Need for local policies on Section 135 of the Mental Health Act 1983}

Sir: There are important differences in the provisions of Sections 135(1) and 135(2) of the Mental Health Act 1983. Section 135(1) applies to people who are not yet admitted to psychiatric facilities. In this case, an approved social worker applies for the warrant, and the named constable to whom it is addressed must be accompanied, in the execution of the warrant, by an approved social worker and a registered medical practitioner. All very clear.

Section 135(2), on the other hand, applies to detained patients who are absent from hospital without due authority. In this case, any constable, or any other person authorised under the Mental Health Act 1983 or under Section 83 of the Mental Health (Scotland) Act 1960 to take or retake a patient may apply for the warrant. In the execution of the warrant, it is not mandatory that the constable must be accompanied by anyone: he or she may be accompanied by a registered medical practitioner, or by any person authorised, under the Act, to take or retake a patient.

Those authorised, under Section 18 of the Mental Health Act 1983, to take or retake a patient, are: an approved social worker, an officer on the staff of the hospital (including nurses and doctors), any constable and any person(s) authorised in writing by the managers 